\title{
Otimização do controle de emissão de enxofre na atmosfera no processo de coqueificação
}

\section{Optimization of sulfur emission control in the atmosphere in the coking process}

\author{
1 Matheus Siqueira Dias mateussiqueiradias@hotmail.com \\ 1 Camila Aparecida Ferreria de Souza Almeida \\ 1 Márcio de Araújo Silveira \\ 1 Tandera Côrtez da Costa \\ 2 Clifford Neves Pinto \\ 2 Venicio Siqueira Filho
}

1 Discente do Curso Sistemas de Informação - UniFOA.

2 Docente do Curso Sistemas de Informação - UniFOA.

\section{Resumo}

Este artigo tem por finalidade contribuir com as solicitações que a UNESCO tem feito ao meio acadêmico e científico em intensificar e produzir trabalhos que visem à redução de poluentes atmosféricos que vêm elevando o nível de gases do efeito estufa, além da chuva ácida. Foca-se em agregar valor ao processo siderúrgico, nas necessidades mais desejadas de todos os envolvidos direta ou indiretamente, quer sejam funcionários do setor siderúrgico, consumidores, moradores próximos ou habitantes deste planeta, o que está de acordo o princípio da necessidade do cliente. $O$ estudo apresenta um modelo matemático implementado num sistema computacional que promoverá simulações de mistura de carvões no processo de coqueificação. Essas simulações visam avaliar, antes da sua execução, a obtenção da mistura menos poluente, levando em conta a exergia, os tipos de carvões, sua disponibilidade e custo, de modo que o sistema poderá eleger de modo otimizado esta mistura. Para essa escolha foi necessário empregar conhecimentos de carboquímica, matemática, sustentabilidade, exergia e pesquisa operacional (método simplex). 0 objetivo é auxiliar a rotina diária do especialista e gestores que escolhem os carvões, oferecendo-Ihes agilidade, eficiência exergética e ambiental, além de controle dos materiais disponíveis para a tarefa.

\section{Palavras-chave}

Coque; otimização; siderurgia; processo de coqueificação; dióxido de enxofre.

\begin{abstract}
This article aims to contribute to the requests that UNESCO has made to the academic and scientific community to intensify and produce works aimed at reducing air pollutants that have raised the level of greenhouse gases, besides the acid rain. It focuses on adding value to the steel making process, in the most desirable needs of all directly or indirectly involved, whether employees of the steel industry, consumers, nearby residents or inhabitants of this planet, which is according to the principle of customer needs. The study presents a mathematical model implemented in a computer system that will promote coals simulation mixtures in the coking process. These simulations aim to obtaining , prior to implementation, access to a cleaner mix, taking into account the exergy, the types of coals, availability and cost, so that the system may optimize the election of the mixture. For this it was necessary to employ knowledge of carbon chemistry, mathematics, sustainability, exergy and research operations (simplex method). The goal is to help the daily routine of the specialist and managers in charge of choosing the coals, providing them agility, exergetic and environmental efficiency, in addition to controlling materials available for the task.
\end{abstract}

\section{Keywords}

coke; optimization; steel; coking process; sulfur dioxide.

\section{Como você deve citar?}

DIAS, Matheus Siqueira et al. Otimização do controle de emissão de enxofre na atmosfera no processo de coqueificação. Cadernos UniFOA, Volta Redonda, n. 29, p. 5-14, dez. 2015. 


\section{INTRODUÇÃO}

Com a grande evolução do processo produtivo mundial, fatores que antigamente eram desprezados ou vistos com menor preocupação, agora já são considerados como essenciais pela maioria dos governos mundiais. Vêm de encontro às premissas básicas declaradas pela Organização das Nações Unidas - UNESCO (2010), promovendo e incentivando pesquisas científicas e a produção de conhecimentos. Estão sendo exploradas cada vez mais as questões ambientais e educacionais, fazendo que a ciência e a cultura desenvolvam estudos e pesquisas envolvendo a sustentabilidade, de forma que estejam com pensamento e atenção voltados para as melhorias ambientais.

A proposta do artigo é desenvolver um estudo multidisciplinar para que se possa calcular e avaliar previamente o processo de coqueificação quanto à sua emissão de poluentes $\left(\mathrm{SO}_{2}\right)$, propondo a melhor forma possível de obter resultados satisfatórios com menor índice de emissão de gases.

Os processos industriais de siderurgia contêm vários controles pós-emissão. Estes geram necessidades de implementação de filtros cada vez mais sofisticados e eficientes. Porém o foco do estudo será nas misturas de materiais usados que geram poluição no processo. É comum em alguns países o não aproveitamento do gás do coque, que gera grandes consequências ao meio ambiente. 0 controle máximo agregado ao melhor processo gera melhor benefício à humanidade. Diante dos fatos relatados acima, motivamo-nos a desenvolver um artigo de forma que contemple as preocupações ambientais, econômicas, exergéticas e operacionais.

\section{MÉTODOS E TÉCNICAS}

Neste projeto de pesquisa, vários foram os métodos e técnicas aplicados no seu desenvolvimento, iniciando-se com uma pesquisa bibliográfica envolvendo conceitos sobre: 1) os processos siderúrgicos envolvendo o setor de carboquímico; 2) sobre poluição ambiental e sustentabilidade; 3) energia e exergia aplicada nos processos envolvidos; 4) aplicando conhecimentos relativos à pesquisa operacional, especificamente sobre o método simplex.

A pesquisa de campo foi efetuada através de consulta e discussões efetuadas com profissionais do setor de carboquímico da Companhia Siderúrgica Nacional, utilizando parâmetros retirados de tabelas e planilhas de misturas de carvões usados na produção de coque, respeitando as premissas básicas de misturas implementadas pela empresa. Gerando as variáveis a serem utilizadas no modelo matemático a ser implementado, verificando seus respectivos limites de trabalho, ou seja, a variação máxima e mínima de teores aceitáveis na referida mistura.

O objetivo principal é auxiliar a rotina diária dos especialistas e gestores que efetuam a escolha dos carvões para produção do coque, permitindo assim, agilizar e eficientizar o processo exergético e ambiental além de controle dos materiais disponíveis para a tarefa.

\section{DESENVOLVIMENTO / EXPERIMENTAL}

\subsection{Conceituando o Processo de Coqueificação}

O carvão aplicado num processo de coqueificação de acordo com as declarações de Eduardo Osório em sua obra: 
Necessita de uma análise sucinta em suas propriedades coqueificantes, isto é, quando aquecido em ausência de ar ele deve amolecer, inchar, aglomerar e, finalmente, solidificar na forma de um sólido poroso e rico em carbono, sendo assim denominado como coque. Os fatores que norteiam a caracterização de um carvão metalúrgico estão diretamente relacionados com a qualidade que o coque deverá possuir, o que, por sua vez, é função dos parâmetros de processo dos altos-fornos. 0 coque, para sua utilização no processo de redução do minério de ferro, efetuada no alto-forno, deve ter determinadas características que são provenientes do carvão de origem. Diante destes fatos, a avaliação de um carvão coqueificante é constituída de ensaios analíticos de caracterização física, petrográfica, química e de testes de laboratório (análise das propriedades plásticas) que tentam simular condições da prática industrial, baseados no processo de fabricação do coque ou nas características exigidas para seu emprego no alto-forno. (OSÓRIO, 2011, p. 12).

Segundo o mesmo autor o processo de coqueificação tenha resultado satisfatório, é necessário que o carvão tenha propriedades coqueificantes, sendo assim, quando aquecido em ausência de ar deverá reagir amolecendo, inchando, aglomerando e por fim solidificando em uma forma porosa e rica em carbono.

Já para Maxwell (2014) a produção de coque em usinas siderúrgicas integradas compreende diferentes etapas, que exigem cuidados especiais quanto à manutenção da qualidade do carvão adquirido, de tal maneira que a qualidade do coque produzido, a partir de tais carvões, não seja comprometida. Pode-se resumir o processo de produção de coque em quatro etapas distintas:

- Recebimento e estocagem dos carvões;

- Recuperação e mistura dos carvões;

- Coqueificação (transformação da mistura de carvões em coque);

- Estocagem e utilização do coque em altos-fornos.

Maxwell (2014) descreve que o transporte de carvões para suprir a demanda das usinas siderúrgicas é função da quantidade, peso e valor do referido carvão. Como a demanda por carvão se dá em grande volume, o seu transporte deve ser feito por meios que possibilitem uma maior capacidade de carga.

Algumas etapas na produção de coque são apresentadas por Eduardo Osório, conforme a seguir:

O processo de produção em algumas etapas, sendo: recebimento, recuperação, processo de coqueificação e utilização do coque em alto forno. 0 processo de coqueificação consiste em um aquecimento de carvões coqueificáveis, em ausência de ar, até cerca de $1100^{\circ} \mathrm{C}$. Ocorre, então, uma decomposição térmica que dá origem aos produtos voláteis e a um resíduo sólido carbonoso, macroporoso e de alta resistência mecânica, chamado coque. A utilização dos produtos voláteis vai depender do tipo de processo de coqueificação empregado. 0 coque pode ser produzido em bateria de fornos com frente de coqueificação vertical ou horizontal. Uma bateria é constituída por vários fornos agrupados (visando economizar energia e espaço), formando uma unidade de produção. (OSÓRIO, 2011, p. 12).

\subsection{Conceituações e Contextualizações do Estudo da Termodinâmica}

O campo da termodinâmica de acordo com Borgnakke (2013, p. 21) se relaciona com a ciência da energia, com foco em armazenamento e processos de conversão de energia. A Poluição do ar é o grande desafio do nosso século, o aquecimento global e as mudanças climáticas, relacionam-se majoritariamente com a emissão de poluentes atmosféricos e dióxido carbônico, bem como de outros gases do efeito estufa, originados principalmente na queima de combustíveis fósseis, utilizados na geração termoelétrica, no transporte e em processos industriais. Esses setores utilizam sistemas de conversão de energia.

Pode-se relacionar a citação de Borgnakke com o objetivo principal deste projeto, no qual o foco é o controle das emissões de poluentes atmosféricos e dióxido carbônico. Tais elementos gerados pelo processo de coqueificação que contribuem para o efeito estufa. 


\subsection{Conceituações e Contextualizações da Exergia}

Segundo a visão de Maxwell $(2014$, p.1) o parâmetro de avaliação termodinâmica, mas também de otimização em um processo é termodinamicamente ideal se a exergia se conserva. 0 aumento da irreversibilidade significa distanciamento do ideal e do ótimo, ela é uma medida de ineficiência do sistema e quanto maior for a perda apresentada pelo processo, menor é a disponibilidade oferecida pelo sistema. Desta maneira, a otimização de um processo termodinâmico implica não exatamente na análise pela conservação de energia (primeira lei da termodinâmica). Num determinado processo, 0 objetivo técnico-econômico não é o de se determinar as perdas de energia, mas as perdas ou destruição de exergia e as irreversibilidades do sistema. Determinar as fontes e as magnitudes das perdas de exergia é quantificar as perdas de capital.

\subsection{Sistema de Gestão de Energia (ISO 50001)}

A Norma ABNT (2011) apresenta a estrutura de melhoria contínua, que comtempla as fases de: Planejar; Fazer; Verificar e Agir e, incorpora a gestão da energia nas práticas organizacionais diárias. A finalidade desta Norma Internacional é permitir que as organizações estabeleçam sistemas e processos necessários para melhorar o desempenho, incluindo a eficácia, uso e consumo de energia. Como todas as ISO's, o processo envolve a melhoria continua e o ciclo PDCA. Os ganhos da inserção da ISO 50001 geram um impacto potencial que influencia em $60 \%$ o uso da energia mundial em diversos setores da economia mundial.

\subsection{Conceituações e Contextualizações da Sustentabilidade}

No mundo sustentável, uma atividade "a econômica", por exemplo, segundo Fernando Almeida relata: não pode ser pensada ou praticada em separado, porque tudo está inter-relacionado, em permanente diálogo.

\footnotetext{
Os desequilíbrios sócio ambientais são o resultado do velho paradigma cartesiano e mecanicista, com sua visão fragmentada do mundo - o universo visto como um conjunto de partes isoladas, funcionando como um mecanismo de relógio, exato e previsível. As transformações cada vez mais rápidas causadas pela tecnologia induzem à instabilidade econômica, ambiental e social, por um lado, e à perda da diversidade natural e cultural por outro. (ALMEIDA, 1992, p. 28).
}

Contextualizando a citação dada acima por Almeida ao projeto, conclui-se que uma atividade econômica deve estar relacionada com o paradigma sustentável, ainda mais dentro de um cenário siderúrgico, onde a emissão de poluentes é muito forte e significativa. 0 desequilíbrio sócio ambiental acontece muitas vezes por falta de "honestidade" e significativo capitalismo industrial.

\subsection{Desenvolvimento Sustentável}

De acordo com Almeida (1992, p. 30) os objetivos e formas de atuação podem ser assim resumidos como:

- Implantar a eco eficiência e a responsabilidade social corporativa (RSC) como um princípio fundamental das empresas de qualquer porte;

- Fomentar a comunicação e o diálogo entre os empresários, o Estado, as ONGs, a comunidade acadêmica e a sociedade em geral;

- Participar da definição de políticas que conduzam ao desenvolvimento sustentável;

- Manter junto às grandes organizações nacionais e internacionais um estreito intercâmbio de informações sobre as melhores práticas em desenvolvimento sustentável. 


\subsection{Gestão Ambiental}

A Gestão ambiental de acordo com Almeida (1992, p. 30) é a forma pela qual a empresa se mobiliza, interna e externamente, na conquista da qualidade ambiental desejada. Os princípios fundamentais da gestão ambiental são:

- Incluir a gestão ambiental nas prioridades da empresa;

- Estabelecer diálogo permanente com as partes interessadas, na empresa;

- Identificar as leis e normas ambientais aplicáveis às atividades, produtos e serviços da empresa;

- Comprometer-se a empregar práticas de proteção ambiental, com clara definição de responsabilidades.

- Estabelecer processo de aferição das metas de desempenho ambiental;

- Oferecer continuamente os recursos financeiros e técnicos apropriados para alcance das metas e avaliação do desempenho ambiental;

- Avaliar rotineiramente o desempenho ambiental da empresa em relação às leis, normas e regulamentos, objetivando o aperfeiçoamento contínuo;

- Implementar programas permanentes de auditoria do sistema de gestão ambiental, para identificar oportunidades de aperfeiçoamento do próprio SGA e dos níveis de desempenho;

- Harmonizar o SGA com outros sistemas de gerenciamento da empresa, tais como saúde, segurança, qualidade, finanças e planejamento.

\subsection{Políticas e Direito Ambiental}

Conforme descrito por Buendia (2011, p. 23) a Política Nacional do Meio Ambiente é instituída pela Lei $n^{\circ} 6.938 / 1981$, tem por objetivo a preservação, a melhoria e a recuperação da qualidade de vida. Definindo ainda: conceitos, objetivos específicos, diretrizes e institui o Sistema Nacional do Meio Ambiente.

0 autor ainda declara que:

[...] incentivar a preservação e a conservação ambiental é responsabilidade da sociedade como um todo: Poder Político, intuições [...] empresas, entidades em massa, empresas, entidades de classe, instituições públicas e privadas e organizações não governamentais. (BUENDIA, 2011, p. 23).

\subsection{Sistema de Gestão Ambiental}

Segundo Almeida (1992, p.58) o Sistema de gestão ambiental (SGAs), apresentado nas normas ISO 14000 ou sistemas setoriais específicos podem abrir oportunidades de eco eficiência para produtos e processos de maneira controlada. As empresas devem implementar um sistema de gerenciamento, aplicar a certificação/verificação e manter esse sistema funcionando para atingir as melhorias planejadas.

\subsubsection{Análise da Sustentabilidade em Gestão de Processos Siderúrgicos}

As barreiras entre a área econômica e a sustentabilidade são muitas, conforme Jaques Marcovitch relata:

[...] observa-se que existem barreiras associadas à competitividade e sustentabilidade ambiental do setor. Ainda que ele se coloque como um baixo emissor de gases poluidores em função do uso de carvão vegetal e energia elétrica, não possui políticas definidas sobre a adoção de metas setoriais. Tais emissões podem ser muito superiores ao se considerar a produção de carvão vegetal de florestas nativas, controladas por empresas que adotam práticas favoráveis ao desmatamento. Além disso, a reciclagem do aço é dificultada pela baixa disponibilidade de sucata se comparada aos patamares norte-americanos e europeus. (MARCOVITCH, 2009, p. 29).

Contextualizando Marcovitch pode-se notar que mesmo o carvão vegetal utilizado na siderurgia sendo de baixa emissão de gases poluentes, as emissões podem ser muito superiores considerando 
a produção de carvão com adoção de boas práticas contra o desmatamento. Aliar o processo com objetivos sustentáveis necessitam de estratégia.

\subsection{Um Modelo de Pesquisa Operacional a Ser Definido}

Para chegar ao modelo desejado foi preciso coletar informações no setor siderúrgico, que foram comparadas e confrontadas com as normas ambientais e necessidades dos produtores para se obter um produto de qualidade.

A primeira ação foi a extratificação de dados referenciais dos produtores do coque para a criação de um modelo "CAIXA PRETA" (termo utilizado para modelagem de pesquisa operacional) que pode ser verificado na Figura 1 a seguir, que atenda às necessidades e restrições do processo produtivo. Foram observadas as normas ambientais vigentes e percebemos a importância de encaixar as restrições do processo a uma realidade matemática tangível. Sendo assim estariam resolvidas as questões exergéticas, ambientais, e de qualidade do processo.

\subsection{Método Simplex}

Dado o alto grau de complexidade da conta, já que pode-se ter de três a cinco carvões, optamos desenvolver um modelo de pesquisa operacional a ser resolvido pelo método simplex.

Figura 1 - Modelo Caixa Preta

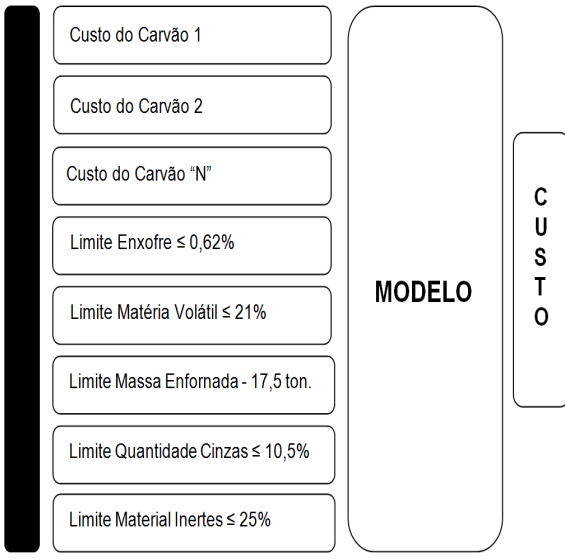

Fonte: dos autores.

Segundo José Carlos Cordeiro Marins, o método simplex é:

\footnotetext{
Um procedimento iterativo que fornece a solução de qualquer modelo de PL em um número finito de iterações. Indica, também, se o modelo tem solução ilimitada, se não tem solução, ou se possui infinitas soluções. (MARINS, 2011b, p. 9).
}

Apoiando-se em Barros (1995) os modelos de códigos computacionais de otimização pelo Método Simplex vem sendo aperfeiçoados por vários autores, mas sempre apresentando limites de uso. Os modelos mais baratos não calculam mais de três produtos. Os mais caros calculam, mas são de custo elevado. Já são conhecidas em publicações de fóruns de internet algumas soluções, mas, em boa parte, limitadas à inserção de no máximo três produtos para serem calculados. 
Dada a disponibilidade de vários carvões para o processo de coqueificação, disponibilizaremos uma simulação do modelo a ser resolvido pelo método simplex. A matemática do Método Simplex resolve equações como esta.

Exemplo: Achar o valor de $x, y$ e $z$, sendo que z será maximizado ou minimizado:

$$
\begin{aligned}
& Z=1 x+2 y+3 z=? \\
& 2 x+3 y+z \leq 35 \\
& 3 x+32 y+z \leq 8 \\
& 45 x+22 y+21 z \leq 4
\end{aligned}
$$

Então, partindo da modelagem da Pesquisa Operacional, chegamos a um modelo específico para nossos objetivos.

\subsubsection{Modelagem}

Propõe-se um modelo matemático para a mistura de diferentes carvões, de modo que se possa obter o coque dentro das especificações desejadas. Acharemos o custo da mistura e limites que devem ser respeitados. Para tanto selecionamos as seguintes restrições no processo de Coqueificação. Maximizar a escolha da melhor quantidade de carvão de cada modelo, baseado nos preços e nas seguintes restrições que devem ser respeitadas.

Enxofre(S): $0,62 \%$

Material Volátil: $21 \%$

Massa total a ser enfornada (MT):................................ 17,5 Ton

Cinzas (CZ): $10,5 \%$

Material Inerte (MI): $25 \%$

Dados 3 carvões $I E, A V$, e BC. Levando em conta que 17,5 Toneladas é a capacidade em toneladas do forno:

Equação de maximização do lucro: $Z=42,80 \mathrm{IE}+65,00 \mathrm{CB}+32,83 \mathrm{EH}$ onde 42,80 IE significa custo do carvão IE, respectivamente.

Restrição Enxofre (S): 1,0IE + 1.0CB + 0.31EH $\leq 0,62 \times 17,5$ onde 1,0 IE significa o limite de Enxofre no carvão IE, respectivamente, vezes a quantidade a ser enfornada.

Restrição Mat. Volátil (MT): 20,02IE + 22,00CB + 20,00EH $\leq 21$ x 17,5 onde 20,02 IE significa o limite de Material Volátil no carvão IE, respectivamente, vezes a quantidade a ser enfornada.

Restrição das Cinzas (CZ): 11,00IE + 8,00CB + 9,00EH $\leq 10,50$ x 17,5 onde 11,00 IE significa a o limite de Cinzas no carvão $I E$, respectivamente, vezes a quantidade a ser enfornada.

Massa Total (MT): $1 I E+1 C B+1 E H \leq 17,5$ onde 1 IE significa a UNIDADE de Massa no carvão IE, respectivamente, vezes a quantidade a ser enfornada.

Material Inerte (IN): $20 I E+23 C B+28,7 E H \leq 10,50 \times 17,5$ onde 20 IE significa o Limite de Inertes no carvão $I E$, respectivamente, vezes a quantidade a ser enfornada. 
Abaixo encontra-se parte da referência de rastreio que o CTRL-S faz.

O programa faz uma sequência de cálculos matriciais:

Tabela 1 - Montagem COM VARIÁVEIS 1,00* de folga.

\begin{tabular}{|c|c|c|c|c|c|c|c|c|c|c|c|}
\hline & IE & CB & EH & $X 4$ & X5 & $\mathrm{X6}$ & $x 7$ & $\mathrm{X8}$ & X9 & $\mathrm{X} 10$ & b \\
\hline$x 4$ & 1,000 & 0,000 & 1,000 & $1,000 *$ & 0,000 & 0,000 & 0,000 & 0,000 & 0,000 & 0,000 & 10,850 \\
\hline x5 & 20,000 & 23,000 & 20,000 & 0,000 & 1,000 * & 0,000 & 0,000 & 0,000 & 0,000 & 0,000 & 367,500 \\
\hline$x 6$ & 11,000 & 10,000 & 8,000 & 0,000 & 0,000 & $1,000 *$ & 0,000 & 0,000 & 0,000 & 0,000 & 183,750 \\
\hline$x 7$ & 1,000 & 1,000 & 1,000 & 0,000 & 0,000 & 0,000 & $1,000 *$ & 0,000 & 0,000 & 0,000 & 17,500 \\
\hline$x 8$ & 20,00 & 44,000 & 23,000 & 0,000 & 0,000 & 0,000 & 0,000 & $1,000 *$ & 0,000 & 0,000 & 437,500 \\
\hline Z & $-48,800$ & $-40,900$ & $-48,800$ & 0,000 & 0,000 & 0,000 & 0,000 & 0,000 & 0,000 & 0,000 & 0,000 \\
\hline
\end{tabular}

Fonte: dos autores.

Tabela 2 - Resultado alcançado

\begin{tabular}{|c|c|c|c|c|c|c|c|c|c|c|c|}
\hline & $\mathrm{X} 1$ & $\mathrm{X} 2$ & X3 & $X 4$ & X5 & X6 & $\mathrm{X7}$ & X8 & $\times 9$ & $\times 10$ & b \\
\hline CB & 1,045 & 1,000 & 0,000 & 1,342 & 0,000 & 0,000 & 0,000 & $-0,015$ & 0,000 & 0,000 & 8,058 \\
\hline$x 5$ & $-0,105$ & 0,000 & 0,000 & $-7,475$ & 1,000 & 0,000 & 0,000 & $-0,632$ & 0,000 & 0,000 & 10,104 \\
\hline$x 6$ & 3,937 & 0,000 & 0,000 & $-0,815$ & 0,000 & 1,000 & 0,000 & $-0,312$ & 0,000 & 0,000 & 38,233 \\
\hline$x 7$ & 0,099 & 0,000 & 0,000 & $-0,240$ & 0,000 & 0,000 & 1,000 & $-0,033$ & 0,000 & 0,000 & 0,436 \\
\hline EH & $-0,144$ & 0,000 & 1,000 & $-1,102$ & 0,000 & 0,000 & 0,000 & 0,048 & 0,000 & 0,000 & 9,006 \\
\hline Z & 14,377 & 0,000 & 0,000 & 51,026 & 0,000 & 0,000 & 0,000 & 0,608 & 0,000 & 0,000 & 819,443 \\
\hline
\end{tabular}

Fonte: dos autores.

\section{A escolha feita foi dos carvões CB em 8,058 ton. + EH em 9,00 ton. $\leq 17,5$ toneladas}

O Custo do total de carvões fica em R\$ $\mathbf{8 1 9 , 0 0 . ~}$

\section{CONCLUSÃO}

O grande propósito a ser extraído deste projeto se dá nas atividades operacionais de uma coqueria em atuar de forma favorável às premissas que a UNESCO vem conclamando ao meio acadêmico, em produzir trabalhos que contribuam para a diminuição dos gases causadores do efeito estufa. Portanto, além de atender às tais necessidades, também foi possível agregar valor ao processo siderúrgico nas necessidades mais desejadas de todos os envolvidos direta ou indiretamente, quer sejam funcionários do setor siderúrgico, consumidores, moradores próximos, habitantes deste planeta e a empresa.

A tecnologia Java abriu compatibilidade de inserção de nosso software com sistemas operacionais utilizados no mundo inteiro, sendo suportado por windows, Mac, aparelhos móveis, telefones entre outros.

A concorrência do mundo globalizado conduz as indústrias a uma busca desenfreada de recursos que muitas vezes esbarram em questões ambientais, sociais, exergéticas e econômicas. Como a siderurgia é essencial no mundo moderno, criamos uma ferramenta que controla a escolha de carvões, necessária no processo siderúrgico, visando otimizar a quantidade de emissão de gases poluentes, 
em especial o enxofre, assim como cinzas, material volátil e materiais inertes. Isto proporcionará uma valiosa contribuição para a redução da poluição, sensível melhoria de vida dos seres vivos em geral.

A pesquisa operacional demonstrou ser uma ferramenta importantíssima e fundamental para o sucesso deste trabalho. Visando utilizar recursos de forma certa, sem desperdício, com base na matemática, aliada a inteligência de negócios transforma e agrega valor a qualquer empreendimento. Para tal, aplicou-se o Método Simplex, capaz de solucionar problemas de otimização.

As normas ambientais conduziram os trabalhos, fazendo parte essencial das restrições a serem respeitadas, aliadas multidisciplinarmente e qualidade do produto. 0 paradigma de gerar menos poluição ou então fazer o melhor produto foi vencido e, com certeza, foi o fator sucesso desta pesquisa.

Diante dos fatos expostos, percebe-se que é possível dar um passo à frente modificando a realidade de hoje, tornando o amanhã melhor. A Ciência aliada ao esforço e o interesse humano são capazes de transformações incríveis. Com o passar do tempo estas transformações tornar-se-ão parte da nova realidade do mundo que desperta para novas descobertas.

O êxito em nosso empreendimento está em tornar evidenciado o controle da emissão de enxofre possível. A partir dessa possibilidade, descobrimos novos desafıos que poderão melhorar ainda mais as pesquisas que serão conduzidas, mediante aos trabalhos aqui produzidos. Existem muitas possibilidades e variáveis que podem incrementar este projeto, como controle de outros gases, de tempo, que poderiam torná-lo muito mais complexo. Mas o foco que tivemos foi de acordo com o interesse do cliente. É provável que a partir desta ferramenta, surjam novas visões que levem a novos desenvolvimentos importantes.

A importância da pesquisa apresentada é um marco em nossas vidas, já que efetivamente ingressamos fundamentadamente nas discussões do desenvolvimento sustentável, uso racional da energia, melhoria da qualidade de vida e economia na produção, com propostas desafiadoras e inovadoras, colocando a serviço da comunidade acadêmica e científica uma proposta bem fundamentada de soluções importantes para a melhoria de todo um conjunto de pessoas. 


\section{REFERÊNCIAS}

ALMEIDA, F. O Bom Negócio da Sustentabilidade. Rio de Janeiro, Nova Fronteira, 1992.

Associação Brasileira de Normas Técnica (ABNT). ABNT NBR ISSO 50.001. Disponível em: <http://www. abnt.org.br/imagens/ABNTNBRISO50001cartilha.pdf>. Acesso em: 28 set. 2014.

BARROS Neto, B. de; SCARMíNIO, I. S; BRUNS, R. E. Otimização Simplex Planejamento e otimização de experimentos, Editora Unicamp, 1995.

BORGNAKKE, C. Fundamentos da Termodinâmica. São Paulo: Blucher, 2013.

MARCOVITCH, Jaques. Study on the Competitiveness of the European Companies and Resource Efficiency. Disponível em: <https://www.google.com.br/ url?sa=t\&rct=j\&q=\&esrc=s\&source=web\&cd=3\&ved=0CC8QFjA CahUKEwi5s8rOnObHAhVFiJAKHYFeD9o\&url=http\%3A\%2F\%2Fec.europa.eu\%2FDocsRoom\%2Fdocuments \%2F5189\%2Fattachments\%2F1\%2Ftranslations\%2Fen\%2Frenditions\%2Fnative\&usg=AFQjCNFLzO8iA MhoeyGb7guSLXHK0SA2ow\&sig2=2uwwIXgc3TCNopBoMclV>. Acesso em: 22 set. 2014.

MARTINS, José Carlos Cordeiro. Gerenciando Projetos de Desenvolvimento de Software com PMI, RUP e UML. 4. ed. Rio de Janeiro: Brasport, 2007.

MAXWELL. (s.d.). PUC-RIO. Disponível em: <http://www.maxwell.vrac.puc-rio.br/11326/11326_3.PDF. Acesso em: 28 set. 2014.

OSÓRIO, Eduardo. ABMBRASIL. Fonte: ABMBRASIL, 2011. Disponível em: http://www.abmbrasil.com. br/epss/arquivos/documentos/2011.pdf>. Acesso em: 28 set. 2014.

UNESCO. Monitoramentodos objetivos de educação para todos no brasil. SãoPaulo, Moderna, 2010. Disponível em: <http://unesdoc.unesco.org/ images/0018/001899/189923por.pdf>. Acesso em: 25 set. 2014. 